\title{
Between 1 and 2.5 Hours
}

National Cancer Institute

\section{Source}

National Cancer Institute. Between 1 and 2.5 Hours. NCI Thesaurus. Code C156947.

An indication that something has lasted, occurred during, or totalled between 1 and 2.5 hours. 